\title{
РАБОТА С РАЗНЫМИ ВИДАМИ И ТИПАМИ ТЕКСТОВ В ПРОЦЕССЕ ОБУЧЕНИЯ РКИ В СТРОИТЕЛЬНОМ ВУЗЕ
}

\section{USING DIFFERENT KINDS OF TEXTS IN RFL CLASSES AT A TECHNICAL UNIVERSITY \\ M. Danielian \\ E. Astashchenko}

Summary: The article analyzes a hypothetical system of educational and scientific texts in Russian as a foreign language classes (exactly Russian foreign Languages for Specific Purposes LSP) for student's level $\mathrm{B} 1+$ and the structure of different kinds of tasks. Particular attention is paid to the debatable issue of differentiation and prevention of duplication of professional texts in LSP, that has a specific purposes: the entity of LSP enhances student's ability to acquire knowledge from the technical lectures and understanding of other materials on his future profession from specialists in this field. The linguist's task is to overcome the difficulties depends on the grammatical and lexical features of the construction and technical substyle of scientific speech, and not to explain the «mechanics of liquids and gases», for example. The authors of the article also analyze texts from the latest textbooks of the University of Civil Engineering, which can be favourable for the development of understanding of academic listening and the scientific speech-producing algorithm that foreign students should have, then the authors of the article offers the examples of complex tasks aimed at improving vocabulary and grammar, as well as the formation of the student's communicative competence are given.

Keywords: Russian as a foreign Languages (RFL), Languages for Specific Purposes (LSP), construction and technical substyle, communicative competence, educational and scientific text.

\author{
Даниелян Мери Георгиевна \\ К.филол.н., дочент, НИУ «Московский государственный \\ строительный университет» \\ daniel_mg@list.ru \\ Астащенко Елена Васильевна \\ К.филол.н., стариий преподаватель, НИУ «Московский \\ государственный строительный университет» \\ gedda@inbox.ru
}

Аннотация: В статье анализируется гипотетическая система учебно-научных текстов по языку специальности для иностранных студентов (уровня В1+) и структура разных видов и типов текстов. Особое внимание уделяется дискуссионному вопросу о дифференциации и предупреждению дублирования профессиональных текстов в пособиях и на занятиях, предназначенных повысить языковой уровень студента и его готовность воспринимать лекционный и иной материал по своей будущей профессии от специалистов в этой области. Задачей лингвиста является преодоление трудностей, связанных с грамматическими и лексическими особенностями строительно-технического подстиля научной речи, а не объяснение «механики жидкостей и газов», например. Также авторами статьи анализируются тексты из новейших учебников строительного университета, которые можно плодотворно (для развития понимания и продуцирования студентами текстов по профильным дисциплинам) переделать именно под учебные тексты на занятиях РКИ, затем приводятся примеры комплексных заданий, направленных на усвоение лексики и грамматики, а также на формирование коммуникативной компетенции студента.

Ключевые слова: язык специальности, строительно-технический подстиль, коммуникативная компетенция, учебно-научный текст, научно-популярный текст.

спешки. Начинать работу с профессионально-ориентированными текстами целесообразно лишь на основе учебно-научных материалов, соответствующих будущей специальности слушателей. Однако подобные тексты должны использоваться не только для отработки грамматических конструкций научного стиля речи. Прежде чем использовать учебные тексты, необходимо проанализировать, какие виды речевой деятельности должны быть активизированы. Дублировать на занятиях введения в язык специальности профессиональные тексты без учета конечных коммуникативных целей непродуктивно, а для обучающихся такая трудная рутинная работа не вызывает, как правило, интереса. На первом курсе студенты-иностранцы строительного факультета изучают не только базовые дисциплины (математика, физика), но и узконаправленные, например, геодезию, механику жидкостей и газов. На подготовительном отделении студенты-иностранцы проходят с преподава- 
телями РКИ пропедевтический курс, знакомятся с математическими, физическими и химическими терминами, а во втором семестре по учебному плану у слушателей уже начинаются занятия со специалистами по математике, физике и информатике.

Как показывает практика, у многих из слушателей не возникает проблем в изучении этих дисциплин: язык цифр у них не вызывает затруднений, но незнание терминологии, которой оперирует преподаватель-предметник, а также темп звучащей речи затрудняет восприятие и понимание информации. Вот почему так важно на среднем и завершающем этапе подготовительного отделения вводить работу с учебно-научными текстами для подготовки иностранных студентов к последующим занятиям. При этом особое внимание уделяется аудированию, так как занятия по узкоспециальным дисциплинам проходят в монологической форме: лекции преподавателей, ответы студентов на зачётах и экзаменах. Диалогическая форма применяется на семинарах, например, для разъяснения, уточнения или проверки понимания какой-либо выборочной части лекции. Именно по этой причине на практических занятиях по русскому языку необходимо развивать навыки аудирования. Иностранные слушатели должны не только понимать звучащий текст, но и уметь отвечать на вопросы, анализировать услышанное. Развитие умений и навыков аудирования позволят студентам-иностранцам привыкнуть к лекционному формату, научится слушать и понимать на слух звучащий материал.

В отечественной методике ведутся споры, на основе каких материалов строить учебные тексты для студентов-иностранцев - на сугубо научных или научнопопулярных. В учебных текстах, созданных на основе научно-популярной литературы, преобладает общенаучная лексика, встречаются термины, но нет формальных грамматических конструкций и лексических единиц, присущих научному стилю речи. Научно-популярный подстиль «близок к беллетристике, т.е. в основе произведений научно-популярной литературы лежат научные факты, фактические данные науки, но своеобразно преподнесенные» [2, с. 20]. Своеобразие заключается в сюжете, который предполагает повествовательный текст (о биографии учёного, истории изобретения и т.п.), в присутствии автора и, соответственно, в эмоциональноэкспрессивной лексике, что именно для иностранного студента немаловажно, поскольку он продолжает знакомиться с культурой страны и находится на языковом уровне В1+, когда, согласно российским нормативным документам, иностранец должен осваивать «тексты информационно-публицистического, социально-культурного или социально-бытового характера», «вести беседу на различные темы (в частности, о себе, работе, профессии, интересах, стране, городе, вопросах культуры» [3]. Вводные занятия по научному стилю речи могут быть основаны на учебно-научных и научно-популярных текстах, которые со сути являются переходным этапом от лингвострановедческих к профессионально-ориентированным. Следующим этапом могут служить адаптированные научные тексты, лексический материал которых соответствует профилю слушателей. Предъявляемые учебно-научные тексты должны быть логически структурированы, чтобы слушатели могли определить не только описываемый объект и его характеристики, но и выделить подтемы, заключение и выводы. Как пишет И.Р. Гальперин в монографии «Текст как объект лингвистического исследования», «членение текста зависит о [его] других грамматических категорий [...] непосредственно связано с категориями информации, интеграции и когезии» $[4$, с. 73]. Продуцирование связного текста «в совокупности с экстралингвистическими, прагматическими, социокультурными, психологическими и другими факторами» (Н.Д. Арутюнова) является важнейшим навыком, который необходимо сформировать при изучении языка специальности на РКИ. Когезия важна в разных типах текста (повествовании, описании, рассуждении), но особенно в рассуждении как основе научной речи. Если это текст по геодезии, или любой другой естественнонаучной дисциплине, материал которой почти не зависит от человеческой воли и человеческого представления, то его логика отлична от логики гуманитарного текста, по истории, например, архитектуры. Всегда стоит помнить об «определённой специфики логических рассуждений в определённых областях научной и практической деятельности людей» $[5$, с. 30]. Для подготовки иностранного студента к решению задач по теплогазоснабжению и вентиляции, по инженерной геодезии и др. необходимо ознакомить его с дейктической лексикой (шифтерами), прежде всего, наречиями места (здесь, там) и времени (сейчас, тогда), вводными словами, характерными именно для естественнонаучного подстиля (следовательно, таким образом); употреблением сказуемого, выраженного предикативным наречием (необходимо, нужно, важно) или модальным глаголом со смысловым инфинитивом [6, с. 101] и способом образования отглагольного существительного (проектирование, расчёт, кондичионирование) [7], а также с активными причастиями совершенного вида (рассмотренный / указанный пример), субстантивированными причастиями (следующий, предыдущий) и прилагательными (стандартный, касательная), предикативными пассивными причастиями в форме среднего рода (Әано), принятыми в точных науках аббревиатурами и сокращениями (например, ЧТД от лат. Q.E.D. - quod erat demonstrandum, «что и требовалось доказать») и др. Необходимо напомнить (ранее предлагаемую в УМК для подготовки к ТРКИ І, типа «Дорога В Россию») структуру неопределённо-личного предложения со сказуемым в форме 3 лица единственного числа и безличного предложении с возвратным глаголом (определяется, вычисляется, округляется). Рассмотрим пример из методических указаний О.Д. Самарина «ПРО- 
ЕКТИРОВАНИЕ И РАСЧЕТ СИСТЕМ ВЕНТИЛЯЦИИ И КОНДИЦИОНИРОВАНИЯ ВОЗДУХА» [8, с. 13]: «Определяется ориентировочная площадь сечения воздуховода $\mathrm{f}_{\text {op }^{\prime}} \mathrm{m}^{2}$, по величине $L$ и рекомендуемой скорости движения воздуха $v_{\text {ор }}$ равной 6 - 7 м/с на магистралях и 4 - 5 м/с - в воздухозаборной шахте и на конечных ответвлениях:

$$
f_{o p}=\frac{L}{3600 \times v_{o p}} .
$$

На подобных примерах можно отработать и частые в технических документах и задачах сокращения, в указанном примере ор. - ориентировочный, названия букв латинского и греческого алфавита, а также обратить внимание на римские цифры, с которыми многие иностранные студенты из стран Азии и Африки ещё не знакомы. Также преподавателю языка специальности важно сформировать навык морфемного анализа, чтобы иностранец, видя слова, образованные сложением основ, сращением или сложно-суффиксальным способом, зачастую с интерфиксом, мог догадаться об их «суммарном» значении (ВОЗДУХоВОД - проводит воздух, ВОЗДУХоЗАБОРный - забирает и вытягивает отработанный воздух): «Затем вычисляется предварительный диаметр воздуховода на участке $d_{o p}=1000 \cdot \sqrt{4 \cdot f_{o p} / \pi}=1130 \sqrt{f_{o p}}$, мм», «далее округляется до ближайшего стандартного» $[6$, с. 13]. Также иностранца нужно подготовить к восприятию инфинитива в функции повелительного наклонения, познакомить с определённо-личными предложениями, в научном стиле - с глаголами 2 лица множественного числа. Приведём пример из сборника задач по геодезии В.В. Симоняна, О.Ф. Кузнецова: «Определить, какой длины на плане будет линия на местности, равная $\mathrm{D}=50$ м, если масштаб плана 1:1000 [...] Переводим численный масштаб 1:1000 в линейный $\left(\frac{1}{1000: 100}\right)$ : в 1 см -10 м, тогда I $=50$ м : $10=$ 5 см.» [9].

Значительно облегчает понимание текста его несложное название, посредством которого студент сможет догадаться, о чем пойдет речь. Учебно-научный текст, предъявляемый студентам-иностранцам, должен быть четко структурирован, в нем должен быть представлен план рассмотрения и его раскрытие. В качестве текстового материала может служить учебный текст, в котором наряду с основной темой присутствуют и подтемы, логически дополняющие основную. Учебными материалами могут служить тексты с несложной структурой и четкой логической связью между основной темой и дополняющих ее подтем. Тексты с такой структурой развивают монологическую и диалогическую речь, способствуют расширению не только активного, но и пассивного словаря. Тексты, разделённые на части небольшого объёма, лучше запоминаются, а прозрачная структура членения способствует быстрому пониманию основной мысли. На продвинутом этапе можно использовать несколько небольших по объему текстов, объединенных одной об- щей темой и развивающих ее, или текст, содержащий в себе несколько подтем, изложенных разными способами (наличие схем, таблиц и пр.)

В учебно-научных текстах могут содержаться несколько способов изложения информации: описание, рассуждение, доказательство, определение понятия об объекте, сообщение. Способы изложения могут варьироваться в зависимости от дисциплины. Так, например, в текстах по истории архитектуры или по химии используется описание, а в текстах по физике и математике преобладает рассуждение. В текстах по геодезии присутствуют описание, доказательство и определения. Более того, в текстах по истории архитектуры, присутствует особая «логика гуманитарного знания». Слово в точных науках, как правило, однозначно: «отличается стремлением к точности, однозначности, краткости» $[2$, с. 7]. Трудно не заметить «разницу в использовании логики в естественно-научной и гуманитарных областях. Если в области естественных наук высказывание Все металлы суть электропроводные вещества является общим в обычном смысле, понятие «металл» является строго определенным, так что любая подстановка в функцию-высказывание X - электропроводное вещество вместо $X$ любого элемента из области металлов дает истинное высказывание, то в гуманитарных науках такая однозначность не всегда имеет место» [5, с. 32]. Можно сравнить этот естественнонаучный текст с фрагментом о металлических конструкциях из книги по истории архитектурного стиля Модерн: «В 1895 году ван де Вельде писал: «Промышленность приобщила металлические конструкции и даже индустриальное строительство к искусству. Она возвела инженера в ранг художника» [...] скоро заговорят об «искусстве промышленности и конструирования». Здесь программа промышленного дизайна, высказанная классиком стиля модерн [...] Видимо, вопрос решается не так просто, и осветить проблему слияния или расхождения искусства и промышленности в пределах стиля модерн однозначно невозможно [...] стиль мог дать различные ответы. [...] Этот диалог художника с машиной входит в общую картину взаимоотношений техники, промышленности, с одной стороны, и художественного творчества - с другой» [10, с. 43]. Важно подготовить студента строительного вуза, где также есть профессиональные образовательные программы «Архитектура», «Реконструкция и реставрация архитектурного наследия», что логика и язык у гуманитарной науки иной, нежели у точной. Часто есть образ автора, деятеля, поэтому используются вводные конструкции, выражающие не только порядок мыслей, последовательность изложения (во-первых, следовательно), но и вводные конструкции, означающие степень уверенности говорящего (наверное, видимо), способ выражения (другими словами, иначе говоря) и даже различные чувства автора (к счастью, $к$ сожалению). Определения в гуманитарном научном подстиле могут быть многозначны (что зачастую оговаривается, как, например, дефиниции «модерн»-»модернизм»), а изображаемые события - амбивалентны и противоре- 
чивы, что нередко подчёркивается вводной конструкцией «с одной стороны, с другой —» с эллипсисом синтаксем. Наряду с рассуждением, в гуманитарном научном тексте всегда присутствует описание, часто - повествование. Для подготовки иностранца к экфрасисам зданий и сооружений необходима иная подготовка, нежели к диегесису, последовательности событий: «Архитекторы Возрождения занимались строительством всех типов зданий и сооружений [...] Они строили мосты, фортификационные сооружения, занимались водопроводными системами [...] Архитекторов привлекали для строительства декораций во время праздников, карнавалов, в честь побед» [11, с. 31]. В первом случае надо пополнить лексический запас прилагательными, во втором - глаголами. Существительные, означающие архитектурные объекты (акведук, арка) или элементы (вант) и способы проектирования и строительства нужно выучить, как и любые термины. Можно предложить игру (типа «Alias», «Шляпа», «Крокодил»), когда один студенты «загадывает» строительный термин, а другой угадывает по описанию, можно - «перевёрнутое обучение» («flipped classroom»), когда студенты, запомнив термины и самостоятельно отработав грамматические конструкции научного стиля, выступают в классе с презентацией по архитектуре в роли докладчиков, защитников проекта, «преподавателей» дисциплины, демонстрируют освоение лексики и грамматики иностранного языка на том уровне, когда можно сосредоточиться не на языковой форме, а непосредственно на содержании профильной дисциплины. В этом случае понадобится знание лексической сочетаемости и глагольного управления именно в научном стиле.

Архитектурные и строительные термины, а также грамматические конструкции - чем (5) называется что (1); чем (5) называют что (4); что (1) представляет собой что (4); что (1) является чем (5); что (1) относится к чему (3) - для верной и точной формулировки - можно отрабатывать по практикуму С.Н. Белухиной, М.Г. Даниелян, С.В. Полухиной [7].

Если текст разноструктурный, то очень важно соблюдать логическую связь относительно подтем, например, одна подтема может содержать в себе описание, вторая - доказательство. При пересказе студентами естественнонаучных текстов и математических задач, равно как и при подготовке преподавателями учебно-научных текстов по физике или математике, следует выбрать последовательную (цепную) связь предложений [12] в тексте и избегать неоправданных сокращений, чтобы не только сохранить сверхфразовое единство, но и не нарушить алгоритм решения, которое и является целью для студентов технических вузов. При пересказе текста по гуманитарным дисциплинам студент волен выбрать любую связь предложений, в том числе параллельную, лучевую, хотя, конечно, важно обходиться без дискретной, ассоциативной, циклической связей и даже без присоединительной связи, в которой зачастую используется парцелляция и другие конструкции экспрессивного синтаксиса, характерные более для художественного, нежели для научного стиля.

Практические занятия по русскому языку не должны дублировать в полном объеме темы дисциплин, которые изучают студенты на первом курсе. Текстовой материал должен помогать и подготавливать студентов-иностранцев в освоении их специальности. Поэтому необходимо тщательнейшим способом вычленять основные темы их спецкурсов. Таким образом, учебные тексты, изучаемые на практических занятиях по русскому языку, не повторяют материал профессионально ориентированных дисциплин, а содержат в себе в обобщенном виде наиболее важные аспекты. Учебные тексты по специальности направлены на развитие языковых навыков и умений иностранных студентов. Учебные материалы должны быть распределены как по аспектам речевой деятельности студентов, так и ранжированы по сложности. Так, можно выделить тексты для развития монологической или диалогической речи на профессиональные темы, тексты для просмотрового, поискового или изучающего чтения специальной литературы и др.

Анализируя учебный материал изучаемых студентами дисциплин, можно сказать, что тексты по специальности, как правило, большого объема, но в них однотипные грамматические конструкции, а структура самого текста немногосложна.

Разрабатывая учебные материалы по дисциплине «Инженерная геодезия», тексты формировались по следующим критериям: общее понятие о науке и сфера ее применения; характеристика объекта, его строение (рельеф местности); способы измерения объектов; назначение приборов, их устройство, принцип действия. В учебных текстах, касающихся геодезии, присутствует описание явлений, понятий и процессов, определения терминов. Созданные учебные материалы формально можно разделить на типы текстов, раскрывающих характеристику и свойства объекта, его структуру, форму строения объекта, причину происходящих явлений. Подобные тексты-описания способствуют развитию не только монологической речи, но и запоминанию определенного набора типовых, часто встречающихся определений. Перед тем как студентам предъявляется текст, необходимо провести словарную работу: разъяснить значение терминов, их определения, проанализировать грамматические конструкции, привести их синонимичные варианты. После этого предложить прочитать текст-аннотацию (подробнее см. [13, с. 272; 14; 15; 16, с. 87-90]), состоящий из 3-4 предложений, представляющий собой краткое изложение текста урока. Такая предтекстовая работа поможет студентам сориентироваться в новой теме.

Овладеть научным стилем речи невозможно без по- 
нимания лексических единиц и грамматических конструкций. Практически в каждом учебно-научном тексте можно выделить типовые модели предложений. Понимание таких текстов с опорой на типовые грамматические модели способствуют развитию устной речи, формируют умение воспроизводить тексты в научном стиле. Заучивание текстов наизусть с дальнейшим его пересказом не приносит никаких результатов. Научный текст должен быть, в первую очередь, понят и проанализирован, в противном случае студенты затрудняются в усвоении материала. Знание типовых грамматических моделей научного стиля речи облегчает иностранным учащимся овладеть различными видами речевой деятельности, помогать в передачи прочитанной информации, ответах на вопросы и т.п.

Учебно-научные тексты сопровождаются и тематическими упражнениями. Весьма продуктивными являются задания на сочетаемость наиболее частотных глаголов. Например, при изучении процессуальности действия можно привести ряд глаголов: препятствовать (кому? чему?), достигать (чего?), использоваться (где? как? для чего), превращаться (во что?), ускорять (что?), получать развитие (где? когда?), изменяться (как?), перерасmamb (во что??).

Понять различия в значении синонимичных глаголов позволяют задания на лексическую сочетаемость. Например, образоваться - появиться - зародиться и предупредить ошибки типа: геодезия образовалась (вместо: зародилась, появилась) в глубокой древности.

Грамматические задания позволят студентам-иностранцам находить в тексте типовые модели, понимать их значения, строить с ними предложения. Эти же грамматические модели можно использовать в постановочных заданиях, где необходимо вставить в предложение пропущенные модели, а также использовать их в устной речи, строя монологическое высказывание и используя нужные модели предложения в зависимости от типовых фрагментов текста.

Проверить умения и навыки использования грамматических конструкций научного стиля речи позволяют задания, в которых студенту предлагается рассказать о каком-либо изученном явлении или приборе, о котором говорилось ранее в тексте. При этом студентам даются модели, которые необходимо использовать в устном высказывании.

Для закрепления грамматического материала может быть применен метод моделирования текста с использованием конструкций научного стиля речи. Для этой цели аудитории предлагается текст, написанный в свободной форме, а студентам необходимо трансформировать его в научный. Такие задания развивают коммуникативные навыки и монологическую речь, студент не просто пересказывает выученный текст, а передает прочитанный и понятым материал на научную тему.

\section{ЛИТЕРАТУРА}

1. Мотина Е.И. Язык и специальность: лингвометодические основы обучения русскому языку студентов-нефилологов. - 2-е изд., испр. 一 М.: Рус. яз., 1988. 176 с.

2. Митрофанова 0.Д. Язык научно-технической литературы. М.: Изд-во МГУ, 1973.

3. Уровни владения русским языком как иностранным и требования к ним [электронный ресурс] https://rg.ru/2014/06/20/urovni-dok.html (дата 0бращения: 17.09.2021)

4. Гальперин И.Р. Текст как объект лингвистического исследования. —М.: КомКнига, 2007. 144 с.

5. узнецов В.Г. Логика гуманитарного познания // Философия и общество, №4, 2009. С. 22-63.

6. Котюрова М.Р. Стилистика научной речи. - М.: Академия, 2010. 240 с.

7. Белухина С.Н., Даниелян М.Г., Полухина С.В. Корректировочный курс грамматики русского языка: практикум. М.: НиУ МГСу, 2019.

8. Самарин 0.Д. Проектирование и расчет систем вентиляции и кондиционирования воздуха. М.: НИУ МГСУ, 2007. 21с.

9. Симонян В.В., Кузнецов 0.Ф. Геодезия: сборник задач и упражнений. М.: М.: НИУ МГСУ, 2015. 160 с.

10. Сарабьянов Д.В. Модерн. История стиля. М.: Галарт, 2001. 343 с.

11. Забалуева Т.Р. Основы архитектурно-конструктивного проектирования. М.: НИУ МГСУ, 2015. 196 с.

12. Яшина В.И. Теория и методика развития речи детей: учебник для студ. учреждений высш. проф. образования/ В.И. Яшина, М.М. Алексеева; под общ. ред. В.И. Яшиной. - М.: Издательский центр «Академия», 2013.- 448 с.

13. Колесникова Н.И. От конспекта к диссертации: Учебное пособие по развитию навыков письменной речи. — М.: Флинта: Наука, 2002.288 с.

14. Котюрова М.П. Культура научной речи: текст и его редактирование. [Электронный ресурс]: учеб. пособие / М.П. Котюрова, Е.А. Баженова. - 6-е изд., стер. - М.: флинта, 2018. 280 c.

15. Перфильева Н.П. Подготовка и редактирование научного текста: учеб.-метод. пособие. - М.: Флинта, 2015. 116 с.

16. Аксарина Н.А. Технология подготовки научного текста: Учебно-методическое пособие. - М.: Флинта, 2015. 112 с. 